\title{
An unusual case of quadruple polyorchidism in a human cadaver mimicking bilateral lipoma
}

\author{
Ernest F. Talarico, Jr. ${ }^{1 A B}$, Joseph G. Castaneda ${ }^{2 B}$, Sana M. Wahab ${ }^{2 B}$, Katelyn M. Paulus ${ }^{2 B}$, Jack D. \\ Walsh $^{2 \mathrm{~B}}$, Amy E. Stromberg ${ }^{2 \mathrm{~B}}$, Victoria N. Olson ${ }^{2 \mathrm{~B}}$, Paul J. Janus ${ }^{2 \mathrm{~B}}$, Nicholas R. Rocco ${ }^{3 \mathrm{C}}$ \\ ${ }^{1}$ Department of Anatomy \\ ${ }^{2}$ Department of Biology \\ ${ }^{3}$ Department of Urology \\ ${ }^{A}$ Tan Tao University School of Medicine, Long An Province, Việt Nam \\ ${ }^{B}$ North Park University, Chicago, Illinois, USA \\ ${ }^{c}$ United States Naval Medical Center, San Diego, California, USA
}

\section{SUMMARY}

Polyorchidism is a rare congenital disorder defined as the presence of more than two testicles for which the underlying etiology is unknown. This report examines a novel case, correlates findings to the literature, and discusses potential mechanisms of dysgenesis. This study was conducted on a 96-year-old male cadaver. Meticulous skilled dissection was done with careful attention to the pelvis, the inguinal region, the scrotum and testes. Measurements of the scrotal testes (STs), supernumerary testes (SNTs), scrotal epididymides (SES), supernumerary epididymides (SNEs), ductus deferens (DD) and supernumerary ductus deferens (SDD) were taken, and testicular volume was calculated. Sagittal sectioning of STs, SNTs, SEs and SNEs was performed and, using standard histologic protocol, tissues were processed, stained with H\&E, and examined. His-

Corresponding author:

Ernest F. Talarico, Jr., Ph.D., Department of Anatomy, Tan Tao

University School of Medicine, Tân Đức, Đức Hòa, E. City Đức Hòa Long

An, Việt Nam; Adjunct Professor of Anatomy, North Park University. E-mail: talaricojrernest@gmail.com

Paul J. Janus, Ed.D., Anatomy and Biology Instructor, Department of

Biology, North Park University, 3225 West Foster Avenue, Chicago,

Illinois 60625-4895 USA. E-mail: pjjanus@northpark.edu tological findings supported the anatomical suspicion of high, bilateral inguinal polyorchdism, or tetraorchdism, in this patient. STs and SNTs have normal, gross morphological features. The left SNT was supplied by the testicular artery, and the right SNT by the inferior epigastric artery. Both SNTs and SNEs were infiltrated with adipose tissue, whereas the scrotal homologues were histologically normal. Testicular volumes were 26.5 $\mathrm{cm}^{3}$ and $23.7 \mathrm{~cm}^{3}$, and $12.3 \mathrm{~cm}^{3}$ and $0.55 \mathrm{~cm}^{3}$, for the left and right STs and SNTs, respectively. The left and right SEs measured $7.2 \mathrm{~cm}$ and 7.0 $\mathrm{cm}$; the left and right SNEs measured $4.7 \mathrm{~cm}$ and $1.7 \mathrm{~cm}$, respectively. The left DD measured 40.2 $\mathrm{cm}$ from the scrotum. The SDD from the left SNT measured $5.9 \mathrm{~cm}$ and joined the main ductus $16 \mathrm{~cm}$ proximal to its origin. The right main DD measured $39.2 \mathrm{~cm}$, and the SDD from the right SNT was $3.2 \mathrm{~cm}$ and joined the main DD $17.4 \mathrm{~cm}$

Submitted: November 15, 2021. Accepted: December 6, 2021

https://doi.org/10.52083/VKMZ1059 
proximal to its origin. The current work suggests a novel classification for polyorchidism of Type 3, Subgroup B, or SNT attached to the draining epididymis and vas deferens without reproductive potential and SNT located outside the scrotal sac. Clinicians must correlate anatomical and histological findings in suspected polyorchids to avoid misdiagnosis of SNTs as benign lipomas.

Key words: Anatomy - Congenital disorder Polyorchid - Polyorchidism - Supernumerary Testes - Testicle - Tetraorchidism

\section{ABBREVIATIONS}

Anterior-Posterior (AP)

Centimeter(s) (cm)

Ductus (vas) Deferens (DD)

Embalming mixture (EB mix)

Epididymis (E)

Height (H)

Inferior Epigastric Artery/Vein (IEA/IEV)

Left (Lt)

Length (L)

Length-sagittal (L-SAG)

Pampiniform Plexus (PP)

Right (Rt)

Scrotal Epididymis/Epididymides (SE/SEs)

Scrotal Testis/Testes (ST/STs)

Spermatic Cord (SC)

Supernumerary Ductus (vas) Deferens (SDD)

Supernumerary Epididymis/Epididymides (SNE/ SNEs)

Supernumerary Testis/Testes (SNT/SNTs)

Testicular artery (Ta)

Testicular vein (Tv)

Transverse left-right (TR)

Width (W)

\section{INTRODUCTION}

Polyorchidism or supernumerary testes (SNTs) is a rare congenital disorder defined as the presence of more than two testicles (Bergholz et al., 2007; Bergholz, 2009). A male who has polyorchidism is known as a polyorchid. The first histolog- ically confirmed example of polyorchidism was in 1880 (Ahlfeld 1880; Danrad et al., 2004); however, the first clinical case was reported in 1895 by Lane, as an incidental discovery during exploration of the groin (Lane, 1895; Artul and Habib, 2014; Hassan et al., 2008; Hassan et al., 2014). A survey shows fewer than 200 cases reported in the medical literature (Bergholz and Wenke, 2009; Artul and Habib, 2014; Cohen et al., 2017), with the majority of cases being detected in patients ranging from 4 weeks to 75-years-old and a median age of 17-years-old (Mathur et al., 2002; Bergholz, 2009; Mittal et al., 2018). Further, there are only seven documented cases in the animal kingdom: two horses, two dogs, two cats, and a single hummingbird (Roca-Ferrer et al., 2015; Tamminen et al., 2012; Witt and Bautista, 2011; Aziz et al., 2016).

Polyorchidism often has no symptoms outside the extra testis. When symptoms are present, they may include pain in the scrotum or lower abdomen, or an obvious mass within the scrotum detected upon palpation (i.e., testicular examination) (Dollard, 2011; Sakamoto et al., 2007; Mittal et al., 2018; Otero, 2016). Associated inguinal hernia or undescended testis are not uncommon findings (Artul and Habib, 2014). Because undescended testes are not uncommon in polyorchids, there is also an increased risk or association between polyorchidsm and testicular cancer (Talarico et al., 2018; Avargues et al., 2015). However, symptoms of polyorchidism may be similar to a paratesticular lesion that may derive from a number of structures that surround the testicle within the scrotum; most commonly, they derive from the spermatic cord (Hassan et al., 2014; Hassan et al., 2008). To differentiate polyorchidism from a paratesticular lesion, an ultrasound and magnetic resonance imaging may be done (Arslanoglu, 2013). Aside from paratesticular lesions, there are some commonly associated abnormalities that are associated with polyorchidism. These abnormalities include testicular maldescent (40\%), inguinal hernia (30\%), testicular torsion (13\%), hydrocele (9\%), and malignancy (6\%) (Mathur et al., 2002; Tonape et al., 2012). These abnormalities may draw attention and lead to eventual diagnosis of polyorchidism. 
Usually, the additional testis or testes are on the left side (Artul \& Habib, 2014; Cohen et al, 2017). SNTs are typically not as large as the two normal testes, making polyorchidism more likely to go undetected for a long time. There are four types of polyorchidism (Table 1 and Table 2; Haddock and Burns, 1987; Bergholz 2007; Friedman, 2015). The most common clinical presentation of triorchidism (i.e., presence of a single extra testicle) is painless swelling (Abduljabbar, 2015; Gune and Gune, 2021). The literature shows left-sided triorchidism as compared to the rightsided variant occurs at a 3:1 ratio (Sheah et al., 2004). Even more rare is a polyorchid with the tetraorchidism (4 testes) type, where only 9 cases are cited in the scientific literature (Ibrahim, 2016; Duymus et al., 2016). There are only two reported cases of a polyorchid with five testicles, where in one case all SNTs were located high in the left inguinal canal and in the second case location of SNTs varied between abdomen and left inguinal canal (Zahirian Moghadam et al., 2020).

It has been hypothesized that polyorchidism is a result of duplication or malformation of the gonadal ridge during embryological development (Mittal, 2020; Bergholz 2009; Ellet, 2015). During the division of the gonadal ridge, the primordial testes may be transversely or longitudinally divided. Some investigators suggest that a transverse division results in the duplication of both the epididymis and testis, while longitudinal division results in only duplication of the testis (Méndez-Gallart et al., 2012). Otero (2016) suggested that the mechanism underlying division of the gonadal ridge is the malformation of peritoneal bands over the gonadal ridge, thereby transversely dividing the gonadal ridge. However, Otero's approach only explains transversal division, and not longitudinal division. When only the testis is duplicated, that organ has no reproductive potential and an increased malignant potential (Danrad et al., 2004). A more common finding in polyorchids is duplication of the epididymis and vas deferens, rather than SNTs sharing a single epididymis or vas deferens (Akbar et al., 2003). In contrast, Sheah (2004) suggests that, depending upon the segmentation plane and the site of segmentation along the gonadal ridge, SNTs may develop with a common or single epididymis and vas deferens, and that in most cases the epididymis and vas deferens are shared or missing. Another theory for polyorchidism focuses on the degeneration of parts of the mesonephric duct. After a transverse division of the primordial gonadal ridge, there is

Table 1. Anatomical Classification Scheme of Polyorchidism.

\begin{tabular}{|c|l|l|}
\hline TYPE & DESCRIPTION & THEORETICAL ORIGIN \\
\hline I & $\begin{array}{l}\text { SNT lacks an epididymis or vas deferens and } \\
\text { has no attachment to the usual testis. }\end{array}$ & Division of genital ridge. \\
\hline II & $\begin{array}{l}\text { SNT drain into the epididymis of the usual testis } \\
\text { and they share a common vas deferens. }\end{array}$ & $\begin{array}{l}\text { Division of genital ridge occurs in the region where the primordial } \\
\text { gonads are attached to the metanephric ducts, although the } \\
\text { mesonephros and metanephric ducts are not divided (i.e., } \\
\text { incomplete division). }\end{array}$ \\
\hline III & $\begin{array}{l}\text { SNT have their own epididymis and both } \\
\text { epididymis of the ipsilateral testes drain into } \\
\text { one vas deferens. }\end{array}$ & $\begin{array}{l}\text { Complete transverse division of the mesonephros as well as of } \\
\text { genital ridge. }\end{array}$ \\
\hline IV & $\begin{array}{l}\text { Complete duplication of testes, epididymis and } \\
\text { vas deferens. }\end{array}$ & Vertical division of genital ridge and mesonephros. \\
\hline
\end{tabular}

Table 2. Anatomical - Functional Classification Scheme of Polyorchidism.

\begin{tabular}{|c|l|l|}
\hline TYPE & ANATOMICO-FUNCTIONAL DESCRIPTION & SUBGROUP \\
\hline 1 & $\begin{array}{l}\text { SNT attached to the draining epididymis and vas } \\
\text { deferens with reproductive potential (i.e., Types } \\
\text { II, III and IV). }\end{array}$ & $\begin{array}{l}\text { Type 1 - Subgroup A. SNT located within the scrotum (ortho-topic) } \\
\text { Type 1 - Subgroup B. SNT located outside the scrotal sac (ectopic) }\end{array}$ \\
\hline 2 & $\begin{array}{l}\text { SNT with lack of such an attachment without } \\
\text { having any reproductive potential (i.e., Type I). }\end{array}$ & $\begin{array}{l}\text { Type 2 - Subgroup A. SNT located within the scrotum (ortho-topic) } \\
\text { Type 2 - Subgroup B. SNT located outside the scrotal sac (ectopic) }\end{array}$ \\
\hline
\end{tabular}


an attachment to part of the mesonephric duct. The attachment may induce testicular duplication. Support for this model arises from the observation that the gonadal ridge and the mesonephric duct both need to be duplicated in order for there to be a complete separation of the drainage system and testes (Wolf et al., 1998). However, none of these embryological theories is singularly sufficient to explain polyorchidism pathogenesis (Zahirian Moghadam et al., 2020). Interestingly, in only $3 \%$ of cases were chromosomal abnormalities reported in a patient with polyorchidism (Artul and Habib, 2014; Spranger et al., 2002; Vasaiya et al., 2021). Yet, a review of medical literature on the subject shows a lack of research into potential genetic factors that might lead to polyorchidism.

This symposium presents the case of a polyorchid discovered in the normal course of undergraduate, gross anatomical dissection of a male cadaver. This case is unique, because of the advanced age of the polyorchid, the Type IV or tetraorchidism variant, SNTs bilaterally located, and one SNT being supplied by the ipsilateral, inferior epigastric artery. Findings are correlated to a survey of the current literature, and potential mechanisms are discussed.

\section{MATERIALS AND METHODS}

\section{Cadaveric Specimen}

This study was conducted on a 96-year-old male cadaver as part of the Advanced Human Cadaver Laboratory at North Park University (Chicago, Illinois, USA), and with consent of the Anatomical Gift Association of Illinois (Chicago, Illinois, USA). Medical and hospital records, and secondary medical history were unavailable. All federal and state guidelines were followed regarding the use and care of cadaveric materials, as well as all regulations set forth by the Anatomical Gift Association of Illinois and North Park University.

The embalming procedure is a 2-phase procedure beginning within the first 24 hours after death. The embalming mixture (EB mix) is 128 oz of Dodge Funeral Home Fixative (The Dodge Company, Batavia, Illinois USA) and 256 oz of water. The first phase of the embalming procedure is a three-step infusion via the carotid artery of three (separate) tanks of EB mix with a Mark $\mathrm{V}$ embalming machine (Mortech Manufacturing, Azusa, California, USA). This is followed in phase 2 with single tank of EB mix via gravity flow. The specimen is stored in a body bag that is placed onto a stainless-steel tray and into the cadaver rack at $62{ }^{\circ} \mathrm{F}$, and then allowed to cure for a minimum of 4 weeks. With respect to the present work, this anatomical donor was embalmed on October 18, 2019, and prosection began August 27,2020 . Thus, this was approximately 10 months cure time, during which the specimen was re-wet, 2-3 times per week with Restorative Solution (The Dodge Company).

\section{Gross Examination and Photography}

Detailed physical examination was performed utilizing a "donor report" (i.e., similar to an autopsy report), where gross observations and quantitative data were collected. Digital photography of the external features and viscera was done using a NIKON D3100 SLR Camera $(B \& H$ Foto \& Electronic Corporation, NY USA) equipped with an 18-55 mm VR NIKKOR Macro lens and a Nikon $40 \mathrm{~mm}$ f/2.8G AF-S DX NIKKOR 2200 VR Micro lens.

\section{Dissection}

Dissection of the inguinal canals, scrotum, spermatic cords, epididymides and testes were done in the standard fashion. Briefly, with the cadaver in supine position, the integument and superficial fascia were removed from the anterior and lateral abdominal wall. Each of the anatomical structures contributing to the inguinal canal were identified (i.e., oblique, internal oblique, and transversus abdominus muscles, lateral and medial crus, intercrural fibers and Poupart's Ligament (i.e., the inguinal ligament). The external oblique aponeurosis was carefully incised to expose the full length of the spermatic cord. This approach was taken because the following anatomical structures contribute to the inguinal canal: inguinal ligament (lateral wall), internal oblique (medial wall), transversus abdominus and the transversalis fascia (floor of the canal). This was done on both left and right sides. 
Bilaterally, the spermatic cord was carefully freed from the surrounding fascia and adipose tissue with blunt dissection. An incision was made in the proximal scrotum, through the integument, dartos and superficial fascia, and was carried down to the distal region. The scrotal spermatic cord was exposed, the gubernaculum testis was cut and the testis freed from surrounding areolar tissue. Next, the spermatic cord was incised and the coverings (i.e., external spermatic fascia, cremaster and internal spermatic fascia) removed to expose the ductus deferens (DD), testicular artery (Ta), and the pampiniform plexus of veins. This was continued proximally and superiorly along the cord and through the deep inguinal ring.

For both scrotal testes (STs) and SNTs, structures attached to the spermatic cord were isolated and cleaned of remaining areolar tissue. The tunica vaginalis was opened, the epididymis was identified, and the testis oriented along a longitudinal axis; allowing for a sagittal cut creating lateral and medial halves (of testis with epididymis). Gross identification included tunica vaginalis, tunica albuginea, epididymis (head, body and tail), DD and testicular vessels, seminiferous tubules and the region of the rete testis.

When masses were identified (i.e., suspected SNTs) along the tract of the inguinal canal or near to the superficial/deep inguinal ring, the same protocol was done with respect to testicular dissection, and a reasonable attempt was made to identify anatomical structures. In a similar fashion, the same was done with components of the spermatic cord attached to the SNTs, and these structures were traced back to their origin.

\section{Measurements}

Measurements of the STs and SNTs, scrotal epididymides (SEs), supernumeraryepididymides (SNEs), and DD were taken in centimeters. Three measurements of each testis were taken: AnteriorPosterior (AP); Transverse left-right (TR); Lengthsagittal (L-SAG).

Because testicular size and volume change in boys/men from childhood through adulthood and an orchidometer was unavailable, testicular volume was calculated using the formula for an ellipsoid: length $(\mathrm{L}) \times$ width $(\mathrm{W}) \times$ height $(\mathrm{H}) \times 0.52$ (Sakamoto et al., 2006). The measurements for the length of the DD and epididymides were taken using the method previously described by Van Lee and Talarico (Van Lee and Talarico, 2020). This method was modified for epididymides, where the thread was placed mid-sagittal (or lengthwise) along each epididymis from the superior most point of the anatomical caput (or head) to the inferior most point of the anatomical cauda (or tail).

\section{Tissue Preparation}

STs and SNTs were removed from the cadaver and placed into trays. Sagittal sections of the left and right ST, SNTs, SEs, and SNEs were obtained in $5 \times 5 \mathrm{~mm}$ increments using a No. 22 scalpel blade and placed into a labeled tissue cassette. Tissues and cassettes were placed into containers with Formal Fixx (Thermo Scientific Shandon, Hampton, NH, USA). After 24 hours, each specimen was transferred to a container with $70 \%$ EtOH for 72 hours. Next, each specimen was paraffin-embedded, sectioned and processed with the standard protocol for H\&E at the University of Chicago Tissue Processing Center (University of Chicago, Chicago, IL, USA).

\section{RESULTS}

\section{Case Report}

The cadaver (i.e., patient) is a 96-year-old, white male, with a cause of death listed as congestive heart failure. No medical records, or other history, was available.

Topographical examination was consistent with a moderately overweighted male without any evidence of cancer or other disease. The glabella and supraorbital margins, the external genitalia, nipples/breast and body hair distribution were normal for age and did not indicate any pituitary or other endocrine disorder, nor androgenetic alopecia. The penis was of normal caliber. Testicles were palpable within the scrotum bilaterally. There was no visual or evidence of hernia or mass in the abdomen or inguinal region. 
Cadaveric dissection documented a total of 4 testicles present in this patient. Two grossly mature testicles were located, one each, in the left and right scrotal sacs separated by the scrotal septum (i.e., scrotal testes (STs)) (Fig. 1A-C). The volumes of the left and right STs were $26.5 \mathrm{~cm}^{3}$ and $23.7 \mathrm{~cm}^{3}$, respectively. Each ST had an epididymis (i.e., SE) that measured $7.2 \mathrm{~cm}$ (left - length) and 7.0 $\mathrm{cm}$ (right - length). The right spermatic cord had a complex and dilated pampiniform plexus that encompassed the testicular artery (Fig. 1A, Fig. 1C) and coursed superiorly from the right testicle within the right, hemi-scrotum to the superficial and deep inguinal rings. The left pampiniform plexus was only slightly dilated in contrast to the contralateral homologous structure, and had an identical, but left-sided, anatomical course (Fig. 1 A-C).

Two mases were identified, one each bilaterally, high up in the inguinal canal and near to the superficial inguinal ring. Each was first thought to be a fatty lipoma because of "fatty-like" appearance and amorphous consistency. However, closer inspection documented a gross morphology of a testis and epididymis for each mass (Fig. 1A, Fig. $1 \mathrm{D}-\mathrm{E}$ ), and thus these masses were then suspected to be SNTs with SNEs. The left SNT appeared grossly mature, with epididymis and testis proper, and with adhesions to the superficial inguinal ring. The volume of the left SNT was $12.3 \mathrm{~cm}^{3}$, and the length of the left SNE was $4.7 \mathrm{~cm}^{3}$. The left SNT had its own branch from the main spermatic cord extending down into the scrotum, and this branch had a testicular artery, sparce pampiniform plexus and a DD. In contrast, the right SNT appeared more atrophied, surrounded by adipose tissue, and was located high within the right inguinal canal and near to the deep inguinal ring (Fig. 1E). The volume of the right SNT was $0.55 \mathrm{~cm}$. Further, the right SNE appeared malformed (and atrophic), and was only $1.8 \mathrm{~cm}$ in length. The right SNT received its blood supply from the right inferior epigastric artery (Fig. 2). The right ST and the left ST and SNT were supplied by the right and left testicular arteries, respectively. Both the right and left testicular arteries originated at the abdominal aorta and followed the usual course through the pelvic cavity into the inguinal canal.
The left and right ilioinguinal nerves and the genital and femoral branches of the left and right genitofemoral nerves followed the usual anatomical course through the inguinal canal. The ilioinguinal nerves course through the inguinal canal superficial to the spermatic cord and to the mons pubis. The genital branch of the genitofemoral nerve entered the inguinal canal through the deep inguinal ring and accompanied the spermatic cord in the usual fashion on both left and right sides. In contrast, no accessory branches of the left and right ilioinguinal nerves and the left and right genitofemoral nerves coursing along/with the spermatic cord of SNTs were grossly identified.

The DD on the left is joined $16 \mathrm{~cm}$ proximal to its origin by a $5.9 \mathrm{~cm}$ supernumerary ductus deferens (SDD) arising from the left SNT, then the main branch followed the normal course through the inguinal canal to the posterior-inferior urinary bladder. The total length of the DD arising from the left SE was $40.2 \mathrm{~cm}$. The DD from the right ST also followed the normal anatomical pathway. However, the SDD from the right SNT was $3.2 \mathrm{~cm}$ (visible) and did not join that DD arising from the right ST until approximately $17.4 \mathrm{~cm}$ proximal to the origin at the epididymis. The total length of the main right DD was $39.2 \mathrm{~cm}$. These measurements are summarized in Table 3.

\section{Histological Evaluation}

Histological examination of the left and right STs (Fig. 3A and Fig. 3B - main panel) documents that the seminiferous tubules show a clear lumen. Spermatogonia, Sertoli nuclei, spermatocytes, and spermatids can all be observed. The tubular basement membrane is seen, and the interstitium contains a few Leydig cells, blood vessels and fibrous components. The tubules of the left and right SEs (Fig. 3C and Fig 3D - insert) are lined with tall ciliated pseudostratified columnar epithelium. Cilia are stereocilia type. Spermatozoa and debris are seen in the lumen of the tubules. Smooth muscle is identified around the tubules. Photomicrographs of the SNTs (Fig. 3C and Fig. 3D - main panel) and SNEs (Fig. 3C and Fig. 3D - insert) lack the normal histologic morphology, and instead show adipose tissue. 


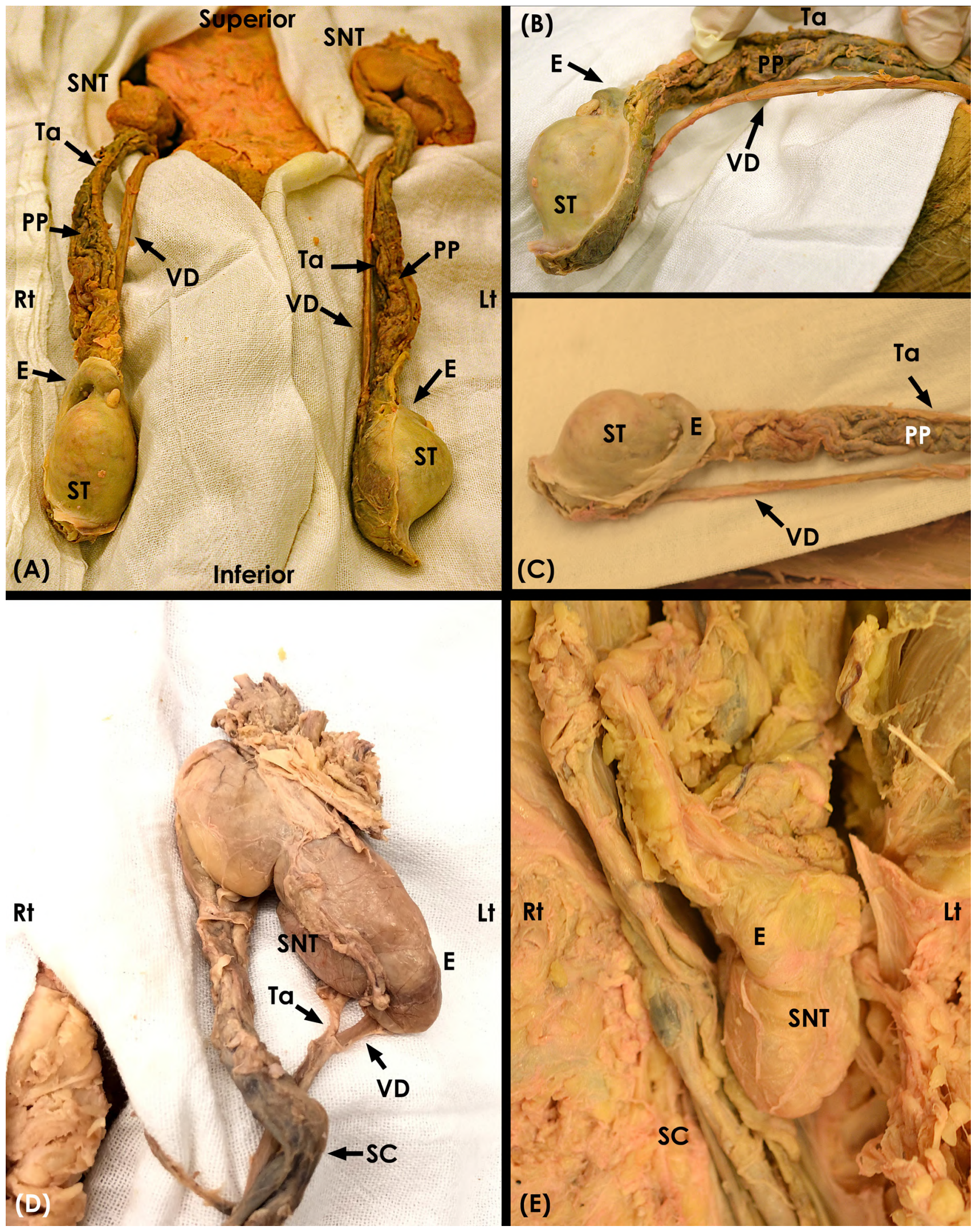

Fig. 1.- Gross Prosection of Testes. (A) Survey view. (B) Left scrotal testis with components of the spermatic cord and epididymis. (C) Right scrotal testis with spermatic cord and epididymis. (D) Left supernumerary testis (SNT). The left SNT has its own testicular artery and ductus deferens that branch from the main (scrotal) spermatic cord (SC). (E) Right supernumerary testis (SNT). The right SNT is more atrophied that the left SNT, and it is also higher up in the inguinal canal near to the deep inguinal ring. [The color on some of the labels in figure panels was changed from "black" to "white" to better visualize the indicated structures. Abbreviations: Ductus (vas) Deferens (VD), Epididymis (E), Left (Lt), Pampiniform plexus (PP), Right (Rt), Scrotal Testis (ST), Supernumerary Testis (SNT), Testicular artery (Ta)]. 


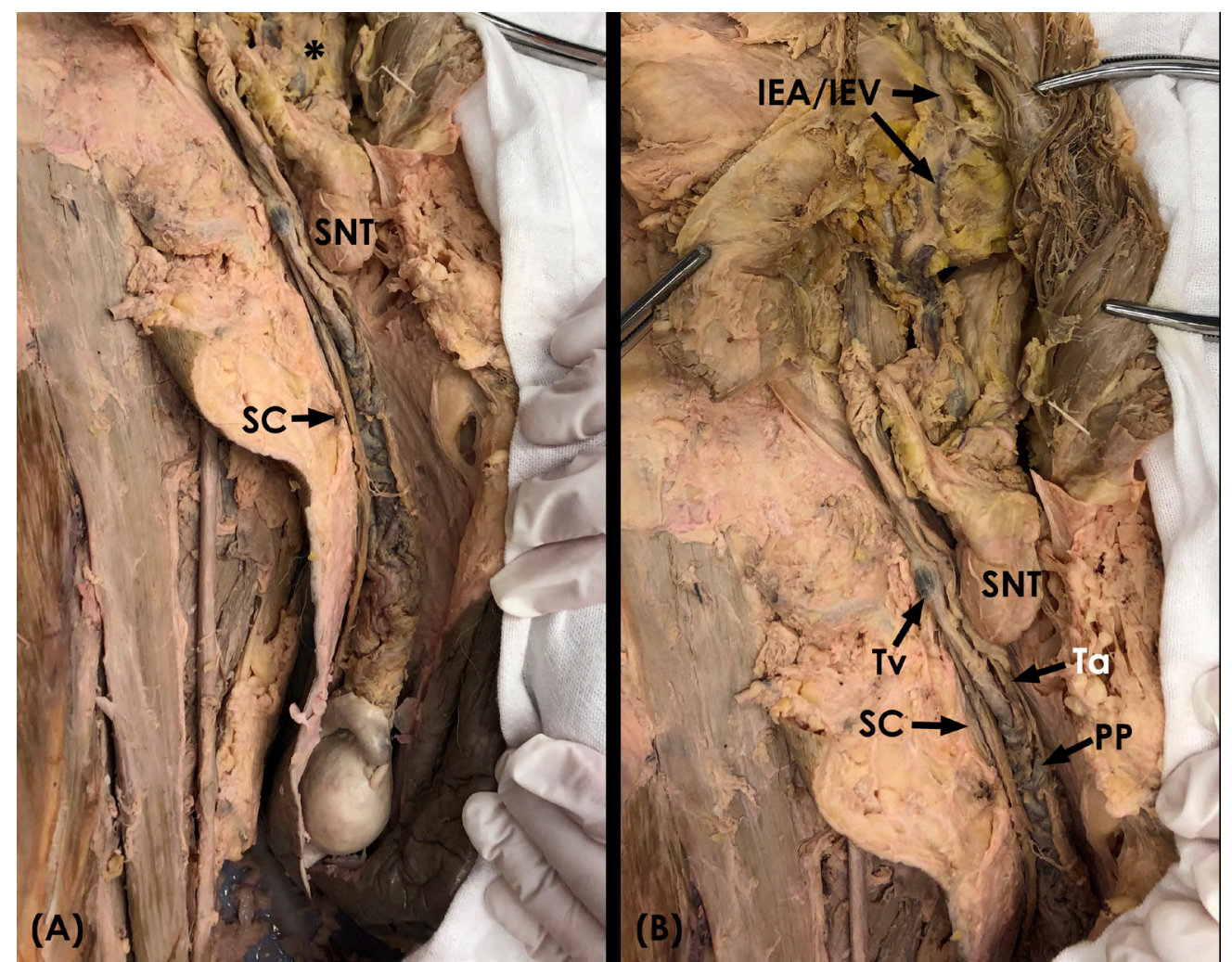

Fig. 2.- Vascular Support to Right Supernumerary Testis. (A) Survey view with right scrotal testis and spermatic cord. The Supernumerary Testis can be observed high in the right inguinal canal. The vessels (i.e., artery and vein) are indicated by the asterisk. (B) This prosected view shows the inferior epigastric vessels (artery is pink; vein is blue) that can be traced down to the right supernumerary testis. The testicular artery (Ta) and vein (Tv) to the right scrotal testis can be seen independent from the inferior epigastric vessels. [The color on some of the labels in figure panels was changed from "black" to "white" to better visualize the indicated structures. Abbreviations: inferior epigastric artery (IEA), inferior epigastric vein (IEV), spermatic cord (SC - testicular artery, pampiniform plexus (PP) and ductus deferens), supernumerary testis (SNT)].

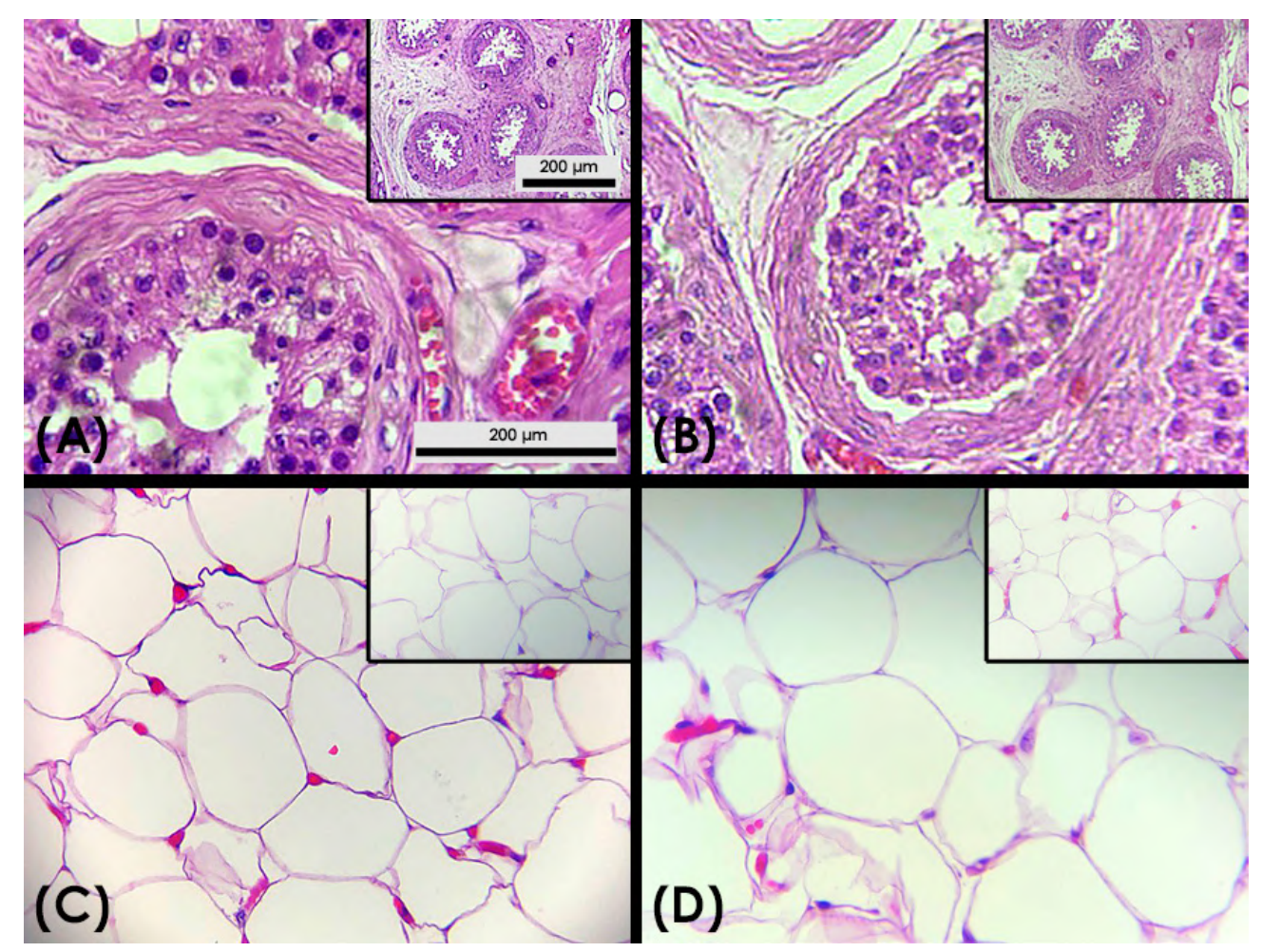

Fig. 3.- H\&E-Stained Slides of Cadaveric Gonadal Tissue Sections. (A) Left scrotal testis and epididymis (insert) with normal morphology. (B) Right scrotal testis and epididymis (insert) with normal morphology. (C) Left supernumerary testis and supernumerary epididymis (insert). Gonadal tissue has been almost totally replaced by adipose tissue infiltrate. (D) Right supernumerary testis and supernumerary epididymis (insert). Similar to the left SNT and epididymis, gonadal tissue has been replaced by adipose tissue infiltrate. Yet, gross photographs document morphologically outlined structures (i.e., testis and epididymis) that appear atrophied and fat-like. [The calibration bars in (A) apply to all images and inserts.] 
Table 3. Measurements.

\begin{tabular}{|c|c|c|c|}
\hline STRUCTURE & MEASUREMENT (cm)* & VOLUME $\left(\mathrm{cm}^{3}\right)^{\mathrm{T}}$ & $\begin{array}{l}\text { REFERENCE VALUE } \\
(\mathrm{cm})\end{array}$ \\
\hline \multirow{3}{*}{ LEFT Testicle } & $3.5 \mathrm{AP}$ & \multirow{3}{*}{26.5} & 3 \\
\hline & $2.8 \mathrm{TR}$ & & $3-4$ \\
\hline & 5.2 L-SAG & & $3-5$ \\
\hline LEFT Epididymis & 7.2 & & $6-7$ \\
\hline LEFT Ductus Deferens & 40.2 & & $20-40$ \\
\hline \multirow{3}{*}{$\begin{array}{l}\text { LEFT SUPERNUMERARY } \\
\text { Testicle }\end{array}$} & $2.9 \mathrm{AP}$ & \multirow{3}{*}{12.3} & 3 \\
\hline & $1.8 \mathrm{TR}$ & & $3-4$ \\
\hline & 4.7 L-SAG & & $3-5$ \\
\hline $\begin{array}{l}\text { LEFT SUPERNUMERARY } \\
\text { Epididymis }\end{array}$ & 4.7 & & $6-7$ \\
\hline $\begin{array}{l}\text { LEFT SUPERNUMERARY } \\
\text { Ductus Deferens }\end{array}$ & $\begin{array}{l}5.9 \text { (joining the main ductus deferens } 16 \mathrm{~cm} \\
\text { proximal to its origin at the epididymis) }\end{array}$ & & $20-40$ \\
\hline \multirow{3}{*}{ RIGHT Testicle } & $3.2 \mathrm{AP}$ & \multirow{3}{*}{23.7} & 3 \\
\hline & $2.9 \mathrm{TR}$ & & $3-4$ \\
\hline & 5.1 L-SAG & & $3-5$ \\
\hline RIGHT Epididymis & 7.0 & & $6-7$ \\
\hline RIGHT Ductus Deferens & 39.2 & & $20-40$ \\
\hline \multirow{3}{*}{$\begin{array}{l}\text { RIGHT SUPERNUMERARY } \\
\text { Testicle }\end{array}$} & $1.2 \mathrm{AP}$ & \multirow{3}{*}{0.55} & 3 \\
\hline & $0.5 \mathrm{TR}$ & & $3-4$ \\
\hline & 3.0 L-SAG & & $3-5$ \\
\hline $\begin{array}{l}\text { RIGHT SUPERNUMERARY } \\
\text { Epididymis }\end{array}$ & 1.8 & & $6-7$ \\
\hline $\begin{array}{l}\text { RIGHT SUPERNUMERARY } \\
\text { Ductus Deferens }\end{array}$ & $\begin{array}{l}3.2 \text { (joining main ductus deferens } 17.4 \mathrm{~cm} \\
\text { proximal to its origin at the epididymis) }\end{array}$ & & $20-40$ \\
\hline
\end{tabular}

"Anterior-Posterior (AP); Transverse left-right (TR); Length-sagittal (L-SAG).

${ }^{\mp}$ Testicular volume was calculated using the formula for an ellipsoid: length $(\mathrm{L}) \times$ width $(\mathrm{W}) \times$ height $(\mathrm{H}) \times 0.52$.

\section{DISCUSSION}

\section{Overall Summary of Results}

In most cases, polyorchidism is incidentally discovered early in life by ultrasonography or surgery when another condition is present, such as inguinal hernia or pain, testicular torsion, maldescent, malignancy, hydroceles and varicoceles, and treated via orchiectomy or orichidopexy. This was not the situation in the current research.
There are several aspects of this case that make it unique and different from any discussed in the published literature. These are:

The patient's age at the time polyorchidism was detected was 96-years. Nearly all the existing literature has been on living patients ranging from infants to middle-aged males.

The patient presents with very high, bilateral inguinal polyorchidism, or tetraorchidism. Few cases of tetraorchidism are recorded in the 
published literature, and none are recorded in an elderly polyorchid (Ibrahim, 2016; Duymus et al., 2016; Sheah et al., 2004).

The left SNT (Fig. 1D) also bears a structure resembling a fully formed epididymis, in contrast to the right SNT (Fig. 1E) in which the suggested epididymis appears with an increased degree of atrophy and adipose infiltration.

The high-degree of adipose infiltration into the SNTs. It is reasonable to suggest that due to the specimen's age that the right SNT atrophied and became fatty since it was not functioning, and both SNTs were infiltrated with fatty tissue resembling lipomas secondary to non-descent and age at time of detection (Hanes and Rosenbloom, 1911; Tasian et al., 2009; Nistal, et al., 2017).

Each SNT had a gross anatomically identifiable (by observation of structure, anatomical relationships and anatomical course) SDD. This is also supportive evidence that the identified masses are not lipomas or testicular nubbins but are SNTs (i.e., lipomas would lack an anatomic DD, and the present SNTs lack fibrosis, calcifications and giant cells).

The right SNT is being supplied blood from the inferior epigastric artery, which usually supplies the abdominal wall and rectus abdominus muscle and not the testis (Fig. 2), in contrast to the left SNT receiving blood in the usual fashion from the left Ta. A survey of the literature reveals no documented case with the branch from the inferior epigastric artery supplying the SNTs or STs.

The anatomical presentation does not fit within the current classification schemes for polyorchidism.

\section{Histology}

Prior literature describes the presence of SNTs; however, few studies supply histological evidence. In some cases, sonography and magnetic resonance imaging are used to confirm the existence of SNTs (Di Cosmo et al., 2016; Abduljabbar, 2015; Artul and Habib, 2014; Arslanoglu, 2013; Baker et al., 1987). In this paper, to confirm that these structures were SNTs, samples were prepared from the left and right
SNTs and compared with tissue samples from both the left and right STs. Histological study with H\&E staining confirmed that the STs contained seminiferous tubules and interstitial cells. This is similar to findings of STs in other studies focusing on polyorchids. In contrast to prior studies in the present work, histological evidence of both SNTs revealed extensive infiltration with adipose tissue, the right greater than left. Prior studies have documented shortening and wall thickening of the seminiferous tubules occurs, as well as a decrease in number of Sertoli cells with an accumulation of abundant lipids (Nistal et al, 2017). Further, other investigations have shown that the morphological findings in adult cryptorchid patients are that (1) testes are much smaller than normal, (2) the tubules are atrophic, (3) the germinal epithelium is generally largely absent, and (4) Leydig-cells are vacuolated and loaded with lipids (Nistal et al., 2017). It is suggested in the present case that because of this polyorchids age and due to SNT non-descent, that components of the undetected SNTs were replaced with fatty tissue (Nistal et al., 2017; Tasian et al., 2009; Hanes and Rosenbloom, 1911). Thus, it is possible that there are more cases of undiagnosed polyorchidism in elderly patients that are misdiagnosed as lipomas, a benign tumor of adipose tissue. Therefore, the findings in the present work suggest that histological study is encouraged to be correlated with gross anatomic findings and anatomical relationships (i.e., arterial supply, DD, etc.) in the confirmational workup of a suspected polyorchid.

\section{A Novel Classification}

Current classification models for polyorchidism are organized under anatomical (Table 1) and anatomical-functional (Table 2) descriptions (Haddock and Burns, 1987; Bergholz et al., 2007). In the patient reported herein, the left SNT and right SNT fit the description of Type IV anatomical (Table 1) but does not fit in any category of the anatomical-functional scheme secondary to lack of reproductive potential. Reproductive potential of the SNTs in this case may have been present early in life and into late teens, however, polyorchidism discovered at 96-years of age showed appropriate and attached anatomical structures with adipose 
infiltration into the testes. Further, the SNTs in the present research are not testicular nubbins. A testicular nubbin is the residual tissue of the human testis after a supposed perinatal vascular accident involving the testicular blood supply. They differ from testicular nubbins because in nubbins there is fibrosis, hemosiderin, giant cells and calcifications (Emir et al., 2007; Cendron et al., 1998). Thus, it is suggested to add a novel Type 3 with Subgroups A and B to the anatomical-function classification scheme; making the classification in this patient Type 3, Subgroup B, or SNT attached to the draining epididymis and vas deferens without having any reproductive potential (i.e., Type 3) and SNT located outside the scrotal sac (ectopic) (i.e., Subgroup B).

\section{Inguinodynia and Possible Correlation to SNTs}

Inguinodynia (i.e., chronic post-herniorrhaphy pain), defined as pain lasting longer than 3 months after open inguinal hernia repair, has become the most important complication after inguinal surgery and therefore compromises quality of life (Konchake et al., 2020). Frequently, males complain of inguinal pain before and after surgery for polyorchidism, inguinal lipomas, or inguinal hernias (Mathur et al., 2002; Tonape et al., 2012; Dollard, 2011; Sakamoto et al., 2007; Mittal et al., 2018; Otero, 2016; Artul and Habib, 2014; Hassan et al., 2014; Hassan et al., 2008). Yet, a survey of the literature does not reveal the documented presence of peripheral (or accessory) inguinal or genitofemoral nerves associated with SNTs or inguinal lipomas. This is consistent with the present work, as well as all other published studies on human polyorchids, that relied on gross anatomical dissection and not microscopic analysis of the spermatic cord. It is possible that microscopic branches of these nerves may be present along the spermatic cords coursing to the SNTs. If so, this is clinically significant in that these nerve fibers may contribute to complaints of pain. Still further, accessory nerve fibers may be clinically significant in the management of chronic groin pain, post operative inguinal pain, or testicular pain following inguinal hernia repair or excision of SNTs (Amid and Chen, 2011; Hue and Chen, 2018; Lange et al., 2015). Thus, a major reason for inguinodynia might be the lack of neuroanatomical knowledge and suboptimal management of the nerves during such surgeries (Konchake et al., 2020).

\section{Embryology and a Possible Genetic Basis for Polyorchidism}

Polyorchidism and the concurrent failure of the SNT to descend into the scrotum may be the result of defective gonadal embryogenesis. Normal development of testes occurs at the genital ridge with subsequent cell differentiation and proliferation (Titi-Lartey and Khan, 2021). Testicular function and development are both dependent on normal Sertoli cell differentiation (Makela et al., 2018). However, the descent of the testes into the scrotum occurs in two stages. The first stage is transabdominal and occurs during weeks 10 - 15 of gestation (Hutson et al, 2013; Titi-Lartey and Khan, 2021). The testes are moving from the abdomen into the inguinal canal. The gubernaculum enlarges during 16 24 weeks of gestation (Favorito et al., 2014). The second stage, or the inguinoscrotal stage, occurs during weeks 25 - 35 of gestation (Favorito et al., 2014). During this phase, the gubernaculum connects the epididymis and the gonad to the forthcoming inguinal canal, eventually pulling (or migrating) the developing testes down into the scrotum. During sexual differentiation, the testes become more attached to the gubernaculum while testosterone causes the mesonephric (Wolffian) duct to form the epididymis and vas deferens (Hutson et al., 2013).

The anatomy of the normal testes is oval shaped and located in the left and right hemi-scrotum separated by the scrotal septum. In the present research, the polyorchid had two mature STs and two SNTs discovered abnormally proximal in the inguinal canals. The left SNT appeared further developed with epididymis and testis proper in comparison to the right SNT, which appeared to be more atrophied and maldeveloped. The left SNT was observed to have adhesions that were attached to the superficial inguinal ring. The left SNT was supplied by its own branch from the left main spermatic cord and included a testicular artery, sparce pampiniform plexus 
and vas deferens. In contrast, the right SNT was supplied by the inferior right epigastric artery but was atrophied and surrounded by adipose tissue. The above results suggest some factor(s) affecting "duplicity" and "migration" of the developing gonads.

A survey of the literature focused on polyorchidism shows little to no mention of genetic factors that may play a role in the development of this condition. It has been hypothesized that polyorchidism is caused by the division of the genital ridge during embryological development (Lawrentschuk and MacGregor, 2004; Friedman, 2015; Satoh, 1991). Based on this theory, it can be suggested that in individuals with polyorchidism there may be a genetic factor that has led to the increased likelihood that anomalous division may occur. Cell-cell adhesion proteins have been identified that play roles in the developing and adult testis in normal testicular development in rats as a model organism (Pipreck et al, 2019). All of these genes for these proteins belong to the Cadherin family of genes: $\mathrm{CDH} 1, \mathrm{CDH} 2$ and CDH3, encode for the proteins $\mathrm{E}$-Cadherin, $\mathrm{N}$-Cadherin and $\mathrm{P}$-Cadherin, respectively. $\mathrm{N}$-Cadherin is proposed to be the most likely candidate, because $\mathrm{CDH} 2$ gene knockout mutants in gonadal germ cells showed significant loss of normal gonadal structure (Pipreck et al, 2019). Therefore, a mutation that reduces the effectiveness of this tissue adhesion molecule could potentially play a role in aberrant division of the genital ridge and the development of polyorchidism. The present work set the stage to explore this potential link between the Cadherin gene family and polyorchidism using full exome sequencing.

\section{Significance of the Current Work}

There are approximately 200 cases of polyorchidsm reported in the literature; the most common variant having three testicles (i.e., left SNT), and only 9 cases of tetraorchidism (i.e., left and right SNTs), and none in an elderly male (Ibrahim 2016). The current research describes an additional and unique case of tetraorchidism with data from gross anatomical and histological perspectives that suggest (1) a novel classification and (2) a hidden presentation mimicking lipoma.
This suggests that some SNTs may be clinically misdiagnosed as lipomas, and therefore are more prevalent than previously recorded. Further, the current work sets that stage for molecular and genetic studies focused on the mechanistic basis of the new classification.

\section{Limitations}

The research was conducted on a postmortem anatomical donor. Access to the comprehensive medical, social and occupational histories of the donor were not available. It is unknown if the donor was aware of the condition, if he had a family history of polyorchidism or reproductive challenges.

\section{CONCLUSION}

This investigation has described a novel case of polyorchidism in an adult male with a cause of death determined as congestive heart failure. This case is interesting because: (1) it differs from the usual time of discovery of polyorchidism, here in a 96-year-old (vs. young) male; (2) it is only the $10^{\text {th }}$ case of tetraorchidism to be discovered; (3) it documents that SNTs may have arterial supply that has not been previously described in the literature (i.e., the inferior epigastric artery); (4) it suggests that lipomas of the inguinal canal may be misdiagnosed and actually be SNTs, and (5) this research proposes a reasonable, novel classification of polyorchidism not presented in the current literature, but supported by gross anatomical data. Although multiple conditions may be associated with polyorchidism, the underlying developmental mechanism has yet to be determined. Further, the present work establishes the foundation for genetic/molecular investigation into this condition. Most commonly, polyorchidism is highly curable with orchiectomy or orchidopexy (for preservation of reproductive potential reproductive function), but an increased risk of testicular cancer remains. To achieve accurate diagnosis and optimal patient outcomes, a multidisciplinary approach is needed with expert knowledge of anatomical and histological correlations. 


\section{ACKNOWLEDGEMENTS}

The authors wish to express their sincere gratitude to the patient and his family, who donated his remains to medical research and education. We also wish to thank the director and staff of Anatomical Gift Association of Illinois (Chicago, Illinois, USA) for their expertise in preparing this anatomical donor's remains for the present study. We also express our sincere appreciation to the team at the University of Chicago Tissue Processing Center (University of Chicago, Chicago, IL, USA).

\section{NOTES ON CONTRIBUTORS}

ERNEST F. TALARICO, JR., serves in the appointments of Adjunct Professor of Anatomy (North Park University, Chicago, Illinois USA); Visiting Professor of Anatomy and Radiology, Medical Student Academic Adviser, and Research Adviser at Tan Tao University School of Medicine (Long An, Việt Nam). He is a founding member of the medical advisory board and founder of the Center for Medical Education and Research at the new Nam Can Tho University Hospital (Can Tho, Việt Nam). Dr. Talarico is a consultant and lead prosector for the Anatomical Gift Association of Illinois (Chicago, Illinois USA), and senior research consultant in the Cardiovascular Research Laboratories, Methodist Hospital (Merrillville, Indiana USA). He created and served as director for the International Human Cadaver Prosection Program, which in 2008 received the award for most outstanding and innovative program in undergraduate and continuing medical education from the AAMC Central Group on Educational Affairs. He is creator of the "Talarico Protocol for Human Gross Anatomy" and is the 2008 recipient of the Partnership Matters Award from the Northwest Indiana Area Health Education Center. In recognition of his work and innovations in anatomical education, in October 2010, Dr. Talarico was inducted as a fellow into the Northwest Indiana Society of Innovators.

JOSEPH G. CASTANEDA is currently a junior, undergraduate student at North Park University (Chicago, Illinois USA) working on a B.S. in Biomedical Sciences. He has served as a prosector in the human gross anatomy laboratory and has created a multi-media presentation focused on aneurysms of brachial plexus that is used to educate other students and prosectors. Mr. Castaneda plans to attend medical school.

SANA M. WAHAB is a 2021 graduate from North Park University (Chicago, Illinois USA). She graduated with a B.S. in Biomedical Sciences. Ms. Wahab was involved in various academic groups including Women in STEM, the American Medical Student Association, the TriBeta Honor Society, as well as cadaveric exploration groups. She also served as a teaching assistant and supplemental instructor for human anatomy.

KATELYN M. PAULUS is a sophomore, undergraduate student in the Pre-Nursing program at North Park University (Chicago, Illinois USA). Ms. Paulus has served in the cadaver prosection laboratory, and she created a multi-media presentation that is used to educate students about the brachial plexus and the muscles innervated.

JACK D. WALSH is an undergraduate student studying Molecular Biology and Biotechnology at North Park University (Chicago, Illinois USA). He holds active memberships in the Tri Beta Biological Honors Society, the American Society for Cell Biology, and the American Society for Biochemistry and
Molecular Biology. Mr. Walsh serves in the Biology Department at North Park University, where he participates in many projects to improve the laboratories as well as maintaining equipment and preparing labs for various classes. He is also involved in multiple research opportunities on campus, where he takes initiative and leadership in preforming directed research and teaching underclassmen so they may continue his research once he graduates this coming May. Currently, Mr. Walsh is in the process of applying to graduate programs in pursuit of his Ph.D. in the fields of Molecular Biology and Biochemistry.

AMY E. STROMBERG graduated from North Park University (Chicago, Illinois USA) in 2021 with a B.S in Biomedical Sciences and a minor in Psychology. She has served as a teaching assistant for anatomy and zoology and has worked as the animal care coordinator for the zoology laboratory. Ms. Stromberg's prior student research focused on the roles of melanism in urban pigeons. She is currently obtaining certification as an emergency medical technician and plans to go on to medical school.

VICTORIA N. OLSON graduated in 2021 from North Park University (Chicago, Illinois USA), Summa Cum Laude with a B.A. in Biomedical Sciences and a minor in Chemistry. She served as an anatomy teaching assistant and an undergraduate learning assistant for advanced physiology, as well as Treasurer of the Beta Beta Beta Honor Society. Ms. Olson created a human cadaver imaging atlas that is being implemented as a learning tool at North Park University. She is a member of the American Medical Student Association and is currently applying to medical school.

PAUL J. JANUS received his Ed.D. in Higher Education and Adult Learning from Walden University (Minneapolis, Minnesota USA). Dr. Janus serves as the Laboratory Manager for the Department of Biology, the Director of Anatomical Research, and a Professor of Biology and Chemistry at North Park University (Chicago, Illinois USA).

NICHOLAS R. ROCCO is a doctor of allopathic medicine; Dr. Rocco graduated from Uniformed Services University of Health Sciences School of Medicine (Bethesda, Maryland USA). Dr. Rocco has completed extensive training in urology, and he serves as a reconstructive surgeon in urology as a member of the Naval Medical Center - San Diego in the Department of Urology (San Diego, California USA).

\section{REFERENCES}

ABDULJABBAR AH (2015) A case report: triorchidism; is a rare mistaken cause for extra testicular neoplasm. Urol Case Rep, 3(3): 89-91.

AHLFELD F (1880) Die Missbildungen des Menschen. Leipzig, Germany: Grunow, 126.

AKBAR SA, SAYYED TA, JAFRI SZ, HASTEH F, NEILL JS (2003) Multimodality imaging of paratesticular neoplasms and their rare mimics. Radiographics, 23(6): 1461-1476.

AMID PK, CHEN DC (2011) Surgical treatment of chronic groin and testicular pain after laparoscopic and open preperitoneal inguinal hernia repair. J Am Coll Surg, 13(4): 531-536.

ARTUL S, HABIB G (2014) Polyorchidism: two case reports and a review of the literature. J Med Case Rep, 8: 464-468.

ARSLANOGLU, A, TUNCEL SA, HAMARAT M (2013) Polyorchidism: Color doppler ultrasonography and magnetic resonance imaging findings. Clin Imaging, 37(1): 189-191.

AVARGUES A, ROGEL R, BROSETA E, LUJÁN S, BETANCOURT JA, MORALES G, BORONAT F (2015) Polyorchidism: the case in a young male and review of the literature. Asian J Androl, 17(3): 511-512. 
AZIZ W, REHMAN KU, RAFIQUE MZ (2016) Doppler ultrasound findings in a patient with primary infertility and triorchidism. BMJ Case Rep, 215346, doi: 10.1136/bcr-2016-21534.

BAKER LL, HAJEK PC, BURKHARD TK, MATTREY RF (1987) Polyorchidism: evaluation by MR. AJR Am J Roentgenol, 148(2): 305-306.

BERGHOLZ R, KOCH B, SPIEKER T, LOHSE K (2007) Polyorchidism: a case report and classification. J Ped Surg, 42(11): 1933-1935.

BERGHOZ R, WENKE K (2009) Polyorchidism: a meta-analysis. $J$ Urol, 182(2): 2422-2427.

CENDRON M, SCHNED AR, ELLSWORTH PI (1998) Histological evaluation of the testicular nubbin in the vanishing testis syndrome. $J$ Urol, 160(3 Pt 2): 1161-1163.

COHEN T, AGARD H, PAREKH N, CLARK C (2017) Management of bilateral undescended bilobed testes and review of the literature. Urology, 110: 213-215.

DANRAD R, ASHKER L, SMITH W (2004) Polyorchidsim: imaging may denote reproductive potential of accessory testicle. Pediatr Radiol, 34(6): 492-494.

DI COSMO, SILVESTRI T, BUCCI S, BERTOLOTTO M, TROMBETETA C (2016) A singular case of polyorchidism, Archivio italiano di urologia, andrologia: organo ufficiale [di] Societa italiana di ecografia urologica $e$ nefrologica, 88(4): 333-334.

DOLLARD DJ, FOBIA JB (2011) Extra scrotal spermatocele causing lower abdominal pain: a first case report. Am J Emerg Med, 29(3): 358.37-39.

DUYMUS M, MENZILCIOĞLU MS, ÇETINÇAKMAK M, AVCU S (2016) A rare case of polyorchidism: four testes. Pol J Radi, 81: 39-41.

ELLETT JD, ROSOFF JS, PRASAD MM (2015) Three testicles in one hemiscrotum: an unusual presentation of polyorchidism. BMJ Case Rep, doi: 10.1136/bcr-2014-206033

EMIR H, AYIK B, ELIÇEVIK M, BÜYÜKÜNAL C, DANIŞMEND N, DERVIŞOĞLU S, SÖYLET Y (2007) Histological evaluation of the testicular nubbins in patients with nonpalpable testis: assessment of etiology and surgical approach. Pediatr Surg Int, 23(1): 41-44.

FAVORITO LA, COSTA SF, JULIO-JUNIOR HR, SAMPAIO FJ (2014) The importance of the gubernaculum in testicular migration during the human fetal period. Int Braz J Urol, 40(6): 722-729.

FRIEDMAN, DAVID (2015) Polyorchidism: a case of supernumerary testes. Sonography, 2(1): 14-16.

GUNE AR, GUNE RP (2021) Triorchidism: a rare case report. Afr J Urol, 27:15:1-3.

HADDOCK G, BURNS HJG (1987) Polyorchidism. Postgrad Med J, 63: 703-705.

HANES FM, ROSENBLOOM J (1911) A histological and chemical study of the fatty matter of normal and cryptorchid testes. J Exp Med, 13(3): 355-364.

HASSAN A, EL-MOGY MS, MOSTAFA T (2008) Triorchidism: a case report and review of similar conditions. Andrologia, 40(4) :265-269.

HASSAN A, ELHANBLY S, EL-MOGY MS, MOSTAFA T (2014) Triorchidism: two case reports. Andrologia, 46(9): 1073-1077.

HUTSON JM, SOUTHWELL BR, LI R, LIE G, ISMAIL K, HARISIS G, CHEN N (2013) The regulation of testicular descent and the effects of cryptorchidism. Endocr Rev, 34(5): 725-752.

HU QL, CHEN DC (2018) Approach to the patient with chronic groin pain. Surg Clin North Am, 98(3): 651-665.

IBRAHIM H, ROBERTS MJ, HUSSEY D (2016) Quadruple orchidopexy for torsion testis in an adolescent with polyorchidism: a case report. Urology, 87: 196-199.

KONSCHAKE M, ZWIERZINA M, MORIGGL B, FÜGGER R, MAYER F, BRUNNER W, SCHMID T, CHEN DC, FORTELNY R (2020) The inguinal region revisited: the surgical point of view: An anatomical-surgical mapping and sonographic approach regarding postoperative chronic groin pain following open hernia repair. Hernia, 24(4): 883-894.

LANE WA (1895) A case of supernumerary testis. Trans Clin Soc Lond, 28: 59-60.

LANGE JF, KAUFMANN R, WIJSMULLER AR, PIERIE JP, PLOEG RJ, CHEN DC, AMID PK (2015) An international consensus algorithm for management of chronic postoperative inguinal pain. Hernia, 19(1): 3343.

LAWRENTSCHUK N, MACGREGOR RJ (2004) Polyorchidism: A case report and review of the literature. ANZ J Surg, 74(12):1130-1132.

MÄKELÄ JA, KOSKENNIEMI JJ, VIRTANEN HE, TOPPARI J (2019) Testis Development. Endocr Rev, 40(4): 857-905.

MATHUR P, PRABHU K, KHAMERSRA HL (2002) Polyorchidism revisited. Pediatr Surg Int, 18(5-6): 499-450.

MÉNDEZ-GALLART R, ESTEVEZ-MARTÍNEZ E, RODRÍGUEZ-BARCA P, GARCÍA-PALACIOS M, BAUTISTA-CASASNOVAS A (2012) Incomplete unilateral polyorchidism (bilobed testicle) mimicking testicular tumour. J Pediatr Surg, 47(11): 2140-2142.

MITTAL PK, ABDALLA AS, CHATTERJEE A, BAUMGARTEN DA, HARRI PA, PATEL J, MORENO CC, GABRIEL H, MILLER FH (2018) Spectrum of extratesticular and testicular pathologic conditions at scrotal MR imaging. Radiographics, 38(3): 806-830.

MITTAL PG, PETERS NJ, MALIK MA, SAMUJH R (2020) Intraoperative dilemmas in polyorchidism: to pex or not to pex!! J Indian Assoc Pediatr Surg, 25(3): 175-177.

NISTAL M, GONZÁLEZ-PERAMATO P, SERRANO Á (2017) Clues in the Diagnosis of Non-tumoral Testicular Pathology. $1^{\text {st }}$ Edition, Springer Nature, Switzerland AG.

OTERO J, BEN-YAKAR N, ALEMAYEHU B, KOZUSKO SD, BORAO F, VATES III TS (2016) A unique case of intraabdominal polyorchidism: a case study. Case Rep Urol, Epub doi: 10.1155/2016/2729614

PIPREK RP, KOLASA M, PODKOWA D, KLOC M, KUBIAK JZ (2019) $\mathrm{N}$-cadherin is critical for the survival of germ cells, the formation of steroidogenic cells, and the architecture of developing mouse gonads. Cells, 8(12): 1620:1-24

ROCA-FERRER J, RODRIGUZ E, RAMIREZ GA, MORAGAS C, SALA M (2015) A rare case of polyorchidism in a cat with four intra-abdominal testes. Reprod Domest Animi, 50(1): 172-176.

SAKAMOTO $\mathrm{H}$, SAITO $\mathrm{K}$, OOHTA $\mathrm{M}$, INOUE $\mathrm{K}$, OGAWA $\mathrm{Y}$, YOSHIDA H (2007) Testicular volume measurement: comparison of ultrasonography, orchidometry, and water displacement. Urology, 69(1): 152-157.

SATOH M (1991) Histogenesis and organogenesis of the gonad in human embryos. J Anat, 177: 85-107.

SHEAH K, TEH HS, PEH OH (2004) Supernumerary testicle in a case of polyorchidism. Ann Acad Med Singap, 33(3): 368-370.

SPRANGER R, GUNST M, KÜHN M (2002) Polyorchidism: a strange anomaly with unsuspected properties. J Urol, 168(1): 198.

SINGER BR, DONALDSON JG, JACKSON DS (1992) Polyorchidism: functional classification and management strategy. Ped Urol, 39(4): 384-388.

TALARICO JR EF, MAS JL, JONES JA (2018) A comprehensive anatomical characterization and radiographic study of stage III testicular cancer in a 31-year-old male patient. Eur J Anat, 22(3): 241256.

TAMMINEN TM, LEINONEN MR, KACK H, ANDERSSON M (2012) A polyorchid dog. Reprod Domests Anim, 47(2): e26-28.

TASIAN GE, HITTELMAN AB, KIM GE, DISANDRO MJ, BASKIN LS (2009) Age at orchiopexy and testis palpability predict germ and Leydig cell loss: clinical predictors of adverse histological features of cryptorchidism. J Urol, 182(2): 704-709. 
TITI-LARTEY OA, KHAN YS (2021) Embryology, Testicle. In: StatPearls, StatPearls Publishing; Available from: https://www.ncbi.nlm. nih.gov/books/NBK557763/

TONAPE T, SINGH G, KOUSHIK P, TUMEPALLI T (2012) Triorchidism: a rare genitourinary abnormality. J Surg Tech Case Rep, 4(2): 126-128.

VAN LE C, TALARICO JR. EF, TRUONG NGUYEN K (2020) The size of intestines in Vietnamese adults. Eur J Anat, 24(3): 169-178.

VASAIYA, MK, SHAH, SM, GOHIL VB (2021) Polyorchidism: A rare case report. Int Surg J, 8(1): 398-400.

WITT CC, BAUTISTA E (2011) Triorchidism in a Hummingbird. Wilson J Ornithol, 123(3): 632-635.

WOLF B, YOUNGSON GG (1998) Polyorchidism. Pediatr Surg Int, 13(1): 65-66.

ZAHIRIAN MOGHADAM T, MOHSENI RAD $\mathrm{H}$, ZANDIAN $\mathrm{H}$, HOSSEINKHANI A (2020) Five testicles in the genital area of a thirteenmonth-old baby: a case report. BMC Urol, 20(1): 128-130. 